\title{
Electrophysiological Changes Related to Childhood Trauma in Patients with Major Depressive Disorder: An Event-related Potential Study
}

\author{
In Soo Heo", Young Joon Kwon", Hwa-Young Lee, Ho Sung Lee ${ }^{1}$, Hee-Jung Yoon ${ }^{3}$, Se-Hoon Shim", Ji Sun Kim ${ }^{1}$ \\ Departments of ${ }^{1}$ Psychiatry, ${ }^{2}$ Pulmonology and Allergy, Soonchunhyang University Cheonan Hospital, Soonchunhyang University College of \\ Medicine, Cheonan, ${ }^{3}$ The Korean Society of Infectious Diseases, Seoul, Korea
}

\begin{abstract}
Objective: Childhood trauma is the most important environmental factor for several psychiatric disorders. Depressed patients with childhood trauma appear to have severe symptoms that frequently recur. This study investigated whether depressed patients with childhood trauma showed attenuated Nogo event-related potentials (ERPs) and source activity during response-inhibition tasks.

Methods: Forty-four patients patients with major depressive disorder (MDD) were instructed to perform a Go/Nogo task during electroencephalography. Sensors and source activities of N2 and P3 of the Nogo ERPs were analyzed. The participants' clinical symptoms were assessed using the Childhood Trauma Questionnaire (CTQ), Beck Depression Inventory, State-Trait Anxiety Inventory, Barratt Impulsivity Scale, and Affective Lability Scale. The participants were divided into two groups (low and high), based on their total CTQ scores.

Results: MDD subjects with high CTQ scores showed significantly decreased Nogo P3 amplitudes at the frontal, frontocentral, central, and parietal electrodes than those with low CTQ scores (all $p<0.01$ ). In Nogo P3, the source activities of the right cuneus, right posterior cingulate cortex, right precuneus, left supramarginal gyrus, and left lingual gyrus were significantly lower in the high CTQ group than in the low one (all $p<0.01$ ). There were significant negative correlations between the total CTQ scores and the Nogo P3 amplitudes in the frontocentral $(p=0.03)$ and parietal regions $(p=0.02)$, which showed lower source activity in the Nogo P3 condition.

Conclusion: Depressed patients with severe childhood trauma showed different Nogo-ERP characteristics, which might reflect inhibitory failure and dysfunction in related brain regions.
\end{abstract}

KEY WORDS: Psychological trauma; Depression; Event-related potentials; Biomarker.

\section{INTRODUCTION}

According to the Diagnostic and Statistical Manual of

Received: April 28, 2021 / Revised: June 21, 2021

Accepted: July 12, 2021

Address for correspondence: Se-Hoon Shim

Department of Psychiatry, Soonchunhyang University Cheonan Hospital, Soonchunhyang University College of Medicine, 31

Suncheonhyang 6-gil, Dongnam-gu, Cheonan 31151, Korea

E-mail: shshim2k@daum.net

ORCID: https://orcid.org/0000-0002-3137-6591

Ji Sun Kim

Department of Psychiatry, Soonchunhyang University Cheonan

Hospital, Soonchunhyang University College of Medicine, 31

Suncheonhyang 6-gil, Dongnam-gu, Cheonan 31151, Korea

E-mail: ideal91@hanmail.net

ORCID: https://orcid.org/0000-0003-2472-4591

Se-Hoon Shim and Ji Sun Kim equally contributed to this study as corresponding authors.
Mental Disorders-5 (DSM-5), psychological trauma refers to an exposure to traumatic experiences, such as threatening or substantial physical violence, threatening or actual sexual violence, or circumstances associated with them [1]. The World Health Organization (WHO) estimates that about a quarter of all adults have been physically abused in childhood, with 1 in 13 males and 1 in 5 females reporting sexual abuse in childhood [2]. Childhood trauma is pathological in nature and causes serious psychological and behavioral disorders such as poor emotional control, unstable interpersonal relationships, and lack of self-awareness. Unlike short-term simple anxiety, it usually lasts throughout the patient's life [3].

In fact, childhood trauma has several effects on one's mental state. It makes patients more susceptible to depres-

(c) This is an Open-Access article distributed under the terms of the Creative Commons Attribution Non-Commercial License (http://creativecommons.org/licenses/by-nc/4.0) which permits unrestricted non-commercial use, distribution, and reproduction in any medium, provided the original work is properly cited. 
sion and anxiety $[4,5]$. People with a history of sexual abuse in childhood have significantly increased depression, higher suicide rate, and overall stress vulnerability, due to neurobiological factors, including hormonal changes. $[4,6,7]$. Moreover, trauma in childhood is associated with intellectual dysfunction and cognitive deficits in both childhood and adulthood [8-10], which is particularly relevant to difficulty in inhibitory control [11]. Childhood trauma contributes to impulsivity or deficits in the executive function in patients with psychiatric disorders [12-14]. In addition, some studies show that childhood trauma is related to affective lability or mood dysregulation in patients with borderline personality disorder or bipolar disorder [15-17]. Bulimia nervosa is one of the effects of childhood trauma on affective lability [18].

Among the conditions listed above, negative childhood experiences are a potential risk factor for major depressive disorders (MDD), and a recent meta-analysis showed that childhood abuse worsens the overall course and treatment outcome of MDD [19]. A link between childhood maltreatment and impulsivity and suicidal behavior in patients with MDD has been suggested [1,6]. In addition, childhood trauma affects cognitive functions such as memory, and executive functions in patients with MDD [20].

These trauma effects can cause long-term changes in brain development [21]. In particular, previous brain imaging studies have reported that childhood trauma is associated with structural changes in the frontal lobe and limbic system [22-25]. In a voxel morphometry study, women who experienced stress early in life had less gray matter in the posterior precuneus than healthy controls [26]. Previous research suggests that childhood maltreatment is accompanied by physiological, hormonal, and biochemical changes that eventually lead to changes in brain structure and function $[27,28]$. These results further suggest that childhood trauma causes a wide range of structural changes in the brain.

The results of these changes can be determined through electroencephalography (EEG). Also, it reflects the prognosis or the severity of symptoms of various psychiatric disorders $[29,30]$. In particular, event-related potentials (ERPs) are a neurophysiological tool used to indicate neural activity related to cognitive processes [31]. Using the $\mathrm{Go} /$ Nogo task, processes such as behavioral or response inhibition can be explored [32]. The Nogo P3 component has been considered to reflect response evaluation, or success of response inhibition, which is included in later inhibitory processes [33]. In addition, it has been suggested that the Nogo effect is more reliable than the Go effect $[34,35]$. Previous studies have shown that adolescents and adults who have experienced childhood trauma show changes in Nogo ERP and the source activity of the frontal lobe, suggesting that impulsivity occurs due to the dysfunction of this region [36,37]. Meanwhile, a history of childhood trauma and depressive symptoms is associated with wide-regional brain networks and brain connectivity in patients with MDD $[38,39]$. Although these changes in brain structure and function in depressed patients with childhood trauma might be reflected in the Nogo task in relation to response inhibition, there have been no reports of neurophysiological differences according to the presence of childhood trauma in patients with MDD.

In these patients, childhood trauma is a potential risk factor, and since it leads to severe symptoms and poor prognosis, the presence of a biomarker capable of detecting the symptoms will greatly aid in understanding the patient's future prognosis. Therefore, this study aimed to compare the difference in the ERP amplitude and latency between the two groups divided by the severity of the trauma, and it identified the relationship between them and the current symptoms such as depression, anxiety, impulsivity, and affective lability. Hence, we hypothesized that MDD patients with severe childhood trauma will have more difficulty in response inhibition or have more impulsivity than those with mild trauma; these characteristics will be reflected in Nogo ERP. In addition, the source activity of Nogo ERP could reflect the dysfunction of the brain regions related to childhood trauma.

\section{METHODS}

\section{Subjects}

Patients who visited the Department of Psychiatry at Soonchunhyang University Cheonan Hospital between July 2020 and December 2020 were enrolled in this study. We included 44 participants (24 males and 20 females, mean age $=[26.95 \pm 8.93]$ year $)$ diagnosed with MDD according to the DSM-5 criteria. Participants with psychotic disorders, bipolar disorder, intellectual disability, neurological or severe medical diseases, a history of alcohol or substance abuse/dependence, or head trau- 
ma were excluded from the study by the screening interviews. Some of the participants had comorbid psychiatric diseases: panic disorder $(n=3)$, attention-deficit/hyperactivity disorder (ADHD) $(n=3)$, somatic symptom disorder $(n=1)$, and anorexia nervosa $(n=1)$. All participants were aged between 19 and 60 years. The Korean version of the Childhood Trauma Questionnaire (K-CTQ) was administered to all the participants. They were allocated to either the high or low CTQ group, based on the total CTQ score using the median score (cut-off score = 48) [40]. Each participant had normal hearing ability. The majority of participants were drug-naïve at the time of the EEG recording. All participants provided written informed consent. This study was approved by the Institutional Review Board and Ethics Committee of Soonchunhyang University Cheonan Hospital, and all experimental protocols were approved by the committee (IRB number: 2020-06-019).

\section{Clinical Measures}

All participants were assessed for childhood trauma using the K-CTQ. The CTQ is an instrument used to assess childhood emotional and physical abuse, sexual abuse, and physical and emotional neglect [41]. The sum score of each subtype measures the type and extent of trauma that the patient has suffered, with higher scores indicating greater severity. The Korean translation version of the CTQ has shown adequate reliability and validity among psychiatric patients (Cronbach's $\alpha=0.88$ ) [42].

To evaluate psychiatric symptoms such as depressive mood, anxiety, impulsivity, and affective lability, we used the Korean versions of the Beck Depression Inventory (BDI), the State-Trait Anxiety Inventory (STAI), the Korean version of the Barratt Impulsiveness Scale-11Revised (K-BIS-11-R), and the Affective Lability ScaleShort Form (ALS-SF). The BDI is a self-reporting examination developed to measure depression and has a high internal consistency (Cronbach's $\alpha=0.93$ ) [43]. The BDI consists of 21 items. Each item's score ranges from 0 to 3, and the total score ranges from 0 to 63 . Higher scores were positively correlated with a severe state of depression [44]. The STAI is a self-reporting examination developed to measure two types of anxiety. It consists of 40 items, and each item's score ranges from 1 to 4 . Higher scores were positively correlated with higher levels of anxiety and this inventory has adequate reliability and validity (Cronbach's $\alpha=0.92)[45,46]$. The BIS is a self-report questionnaire for evaluating impulsiveness, and it consists of three factors: attention impulsiveness, motor impulsiveness, and non-planning impulsiveness [47]. The K-BIS-11-R, which translated this scale into Korean, has proved its reliability and validity for impulsive evaluation (Cronbach's $\alpha=0.78$ ) [48]. The ALS-SF is an 18-item questionnaire measuring rapid changes from euthymic mood to other emotional states, including mood elation, depression, and anger [49]. It has three subscale scores: anxiety/depression (ranging from 5 to 20), depression/elation (ranging from 8 to 32), and anger (ranging from 5 to 20). It has high internal consistency and appears to be a reasonable and efficient measure of affect lability (Cronbach's $\alpha=0.90)$ [50].

\section{EEG Data Acquisition and Analysis}

Subjects were seated approximately $60 \mathrm{~cm}$ away from the computer screen in a relaxed sitting position in a silent room. EEG was acquired using a NeuroScan SynAmps amplifier (Compumedics USA, El Paso, TX, USA) with 64 $\mathrm{Ag} / \mathrm{AgCl}$ electrodes mounted on a Quik Cap. Electrodes were placed as frontal $(\mathrm{Fz})$, central $(\mathrm{Cz})$, and parietal $(\mathrm{Pz})$, and an earth electrode was placed fronto-parietal (FPz), according to the extended 10-20 placement scheme. An electrode was placed infraorbitally to monitor the eye movement. Reference electrodes were placed at the mastoid, and the impedance was $<10 \mathrm{k} \Omega$. The band-pass filter was set at $0.1-100 \mathrm{~Hz}$ and sampled at $1,000 \mathrm{~Hz}$.

The EEG data were processed using CURRY 8 (Compumedics USA, Charlotte, NC, USA). The gross artifacts were rejected by visual inspection by a trained person. Eye movement artifacts were removed using the mathematical procedure in the preprocessing software. Data were filtered using a $0.1-30 \mathrm{~Hz}$ band-pass filter and epoched from $100 \mathrm{~ms}$ pre-stimulus to $600 \mathrm{~ms}$ poststimulus. These epochs were subtracted from the average value of the pre-stimulus interval for baseline correction. If any remaining epochs continued to have significant physiological artifacts (amplitude exceeding $\pm 75 \mu \mathrm{V}$ ) in any of the 62 electrode sites, they were excluded from further analysis. Only artifact-free epochs were averaged across trials and participants for ERP analysis. Based on previous studies showing that Nogo ERP reflected behavioral inhibition, the present study included Nogo trials in ERP analysis. 


\section{Behavioral Task Paradigm}

As stimuli for the Go/Nogo task, we applied the "oddball paradigm" of auditory stimulation. ERPs were elicited binaurally through headphones. The subjects were instructed to press the spacebar as accurately and quickly as possible when the target tone appeared, and not to respond when the non-target tone appeared. There were 400 trials, which consisted of Go ( $85 \%$ probability) and Nogo $(15 \%$ probability) conditions. The target tone (Nogo) was 1,500 Hz, and the non-target tone (Go) was $1,000 \mathrm{~Hz}$, with a 1,500 ms interval before the next trial. These stimuli were generated using the E-Prime software (Psychology Software Tools, Pittsburgh, PA, USA). In the Go/Nogo condition, N200 (the most negative peak between 150 and 350 ms after stimulus onset) and the P300 (the most positive peak between 250 and $500 \mathrm{~ms}$ after stimulus onset) were investigated at the $\mathrm{Fz}, \mathrm{FCz}, \mathrm{Cz}$, and Pz electrodes. The time window we assumed during the trials was based on previous studies. To accumulate behavioral data, Go accuracy, Nogo accuracy, and reaction time were calculated based on the data from the E-prime software. Nogo accuracy was calculated to determine the false alarm rate of responses to non-target stimuli.

\section{Source Activity Analysis}

Standardized low-resolution brain electromagnetic tomography (sLORETA) was used to compute the cortical distribution of the standardized source current density of the Nogo activity. SLORETA is a representative source imaging method for solving the EEG inverse problem [51]. sLORETA assumes that the source activation of a voxel is similar to that of the surrounding voxels for calculating a particular solution, and it applies an appropriate standardization of the current density. The lead field matrix was computed using a realistic head model segment based on the Montreal Neurological Institute (MNI) 152 standard template, in which the three-dimensional solution space was restricted only to the cortical gray matter and hippocampus [52]. The solution space was composed of 6,239 voxels with a $5 \mathrm{~mm}$ resolution. Anatomical labels such as Brodmann areas (BAs) were provided by using an appropriate transformation from MNI to Talairach space [53]. The source images of $\mathrm{N} 2$ and $\mathrm{P} 3$ were analyzed in the Nogo condition, and the time frames used to calculate the $\mathrm{N} 2$ and P3 source images were defined between 150 and $350 \mathrm{~ms}$ and 300 and $550 \mathrm{~ms}$ after stimulus onset, respectively.

\section{Statistical Analysis}

To compare the differences in demographic data, clinical measurements, and behavioral task data, both groups were compared using the chi-square test for categorical variables. In the case of continuous variables, after verifying whether the normality assumption was satisfied by the Shapiro-Wilk test, the Mann-Whitney $U$ test or independent $t$ test was used. N2 and P3 amplitudes and latencies of patients were initially evaluated using repeated measures analysis of variance (ANOVA) with electrodes $(\mathrm{Fz}, \mathrm{FCz}, \mathrm{Cz}$, and $\mathrm{Pz})$ as the within-subject factor, groups (high CTQ vs. low CTQ) as the between-subjects factor, and age as covariates. Multivariate analysis of variance (MANOVA) with age as a covariate was used to compare the Go/Nogo ERP amplitude and latency between the groups. In addition, Spearman's correlation analysis was conducted between Go/Nogo sensors, source activities, and psychological measures. Statistical significance was set at $p<0.05$. All statistical analyses were performed using SPSS (version 23.0; IBM Co., Armonk, NY, USA).

\section{RESULTS}

\section{Subjects}

Table 1 presents the demographic data and clinical measurements of patients with MDD in the high and low CTQ groups. We classified 22 subjects as having MDD with high CTQ, and 22 as MDD with low CTQ. Patients in

Table 1. Demographic and clinical symptoms characteristics for all participants

\begin{tabular}{lccc}
\hline \multicolumn{1}{c}{ Variable } & $\begin{array}{c}\text { High CTQ group } \\
(\mathrm{n}=22)\end{array}$ & $\begin{array}{c}\text { Low CTQ group } \\
(\mathrm{n}=22)\end{array}$ & $p$ value \\
\hline Age $(\mathrm{yr})$ & $29.55 \pm 10.29$ & $24.36 \pm 6.60$ & 0.04 \\
Sex $(\mathrm{n})$ & & & 1.00 \\
$\quad$ Male & 12 & 12 & \\
$\quad$ Female & 10 & 10 & \\
Education $(\mathrm{yr})$ & $13.18 \pm 1.99$ & $13.09 \pm 1.57$ & 0.94 \\
Total CTQ score & $64.41 \pm 14.43$ & $37.36 \pm 5.84$ & $<0.01$ \\
BDI & $31.00 \pm 9.81$ & $26.09 \pm 7.44$ & 0.07 \\
STAl state & $57.36 \pm 11.55$ & $55.86 \pm 13.74$ & 0.58 \\
STAI traits & $60.23 \pm 9.22$ & $58.14 \pm 13.74$ & 0.88 \\
ALS-SF & $43.64 \pm 9.40$ & $36.23 \pm 10.65$ & 0.02 \\
BIS & $79.05 \pm 9.21$ & $77.41 \pm 10.60$ & 0.59 \\
\hline
\end{tabular}

Values are presented as mean \pm standard deviation. CTQ, childhood trauma questionnaire; BDI, beck depression inventory; STAI, state-trait anxiety inventory; ALS-SF, affective lability scale-short form; BIS, barratt impulsiveness scale. 
the high CTQ group were significantly older than those in the low CTQ group. The two groups did not differ significantly in terms of sex $(p=1.000)$ and education $(p=$ $0.867)$. In addition, the ALS-SF score was significantly higher in the high CTQ group $(p=0.019)$. There were no significant differences in BDI, STAI state, STAT trait, or BIS between the groups.

\section{Behavioral Outcomes}

Table 2 presents the Nogo N2 and P3 behavioral

Table 2. Comparison of behavioral outcomes

\begin{tabular}{lccc}
\hline \multicolumn{1}{c}{ Variable } & $\begin{array}{c}\text { High CTQ group } \\
(\mathrm{n}=22)\end{array}$ & $\begin{array}{c}\text { Low CTQ group } \\
(\mathrm{n}=22)\end{array}$ & $p$ value \\
\hline Go accuracy $(\%)$ & $93.18 \pm 12.65$ & $98.95 \pm 2.17$ & 0.05 \\
Nogo accuracy $(\%)$ & $92.77 \pm 11.74$ & $95.68 \pm 6.95$ & 0.32 \\
False alarm rate $(\%)$ & $7.23 \pm 11.74$ & $4.32 \pm 11.74$ & 0.32 \\
Reaction time $(\mathrm{ms})$ & $501.00 \pm 113.03$ & $460.90 \pm 63.45$ & 0.16 \\
\hline
\end{tabular}

Values are presented as mean \pm standard deviation. CTQ, childhood trauma questionnaire.

A

$\mathrm{Fz}(\mathrm{Nogo})$

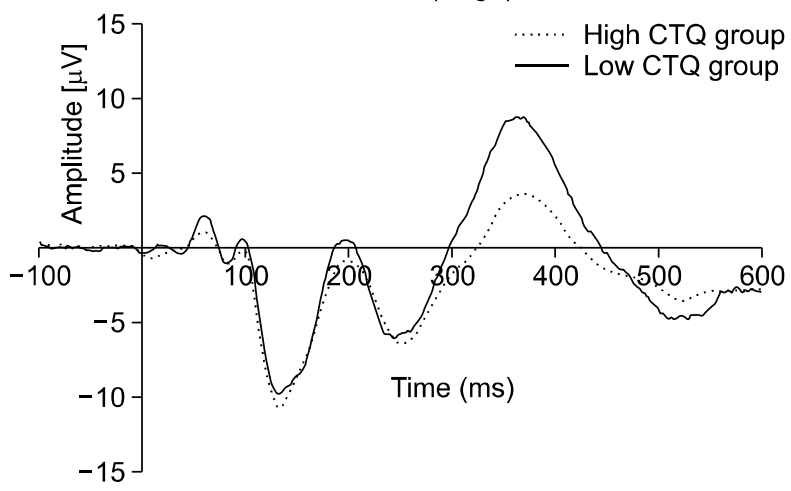

C

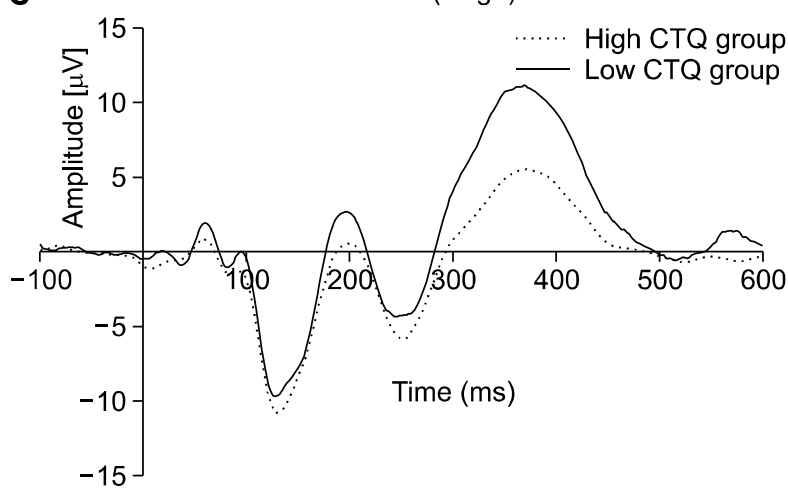

Table 3. Comparison of the amplitudes and latencies in Nogo condition

\begin{tabular}{cccr}
\hline Variable & $\begin{array}{c}\text { High CTQ group } \\
(\mathrm{n}=22)\end{array}$ & $\begin{array}{c}\text { Low CTQ group } \\
(\mathrm{n}=22)\end{array}$ & $p$ value \\
\hline Amplitude $(\mu \mathrm{V})$ & & & \\
N2 Fz & $-8.23 \pm 4.55$ & $-8.55 \pm 6.15$ & 0.98 \\
N2 FCz & $-8.51 \pm 5.22$ & $-8.69 \pm 6.25$ & 0.94 \\
N2 Cz & $-7.51 \pm 4.95$ & $-6.40 \pm 6.61$ & 0.63 \\
N2 Pz & $-4.06 \pm 3.29$ & $-3.83 \pm 5.75$ & 0.95 \\
P3 Fz & $5.43 \pm 3.68$ & $10.90 \pm 7.14$ & $<0.01$ \\
P3 FCz & $6.77 \pm 3.94$ & $12.75 \pm 7.74$ & $<0.01$ \\
P3 Cz & $7.30 \pm 4.34$ & $13.34 \pm 7.71$ & $<0.01$ \\
P3 Pz & $8.02 \pm 4.22$ & $13.42 \pm 6.18$ & $<0.01$ \\
Latency $(m s)$ & & & \\
N2 Fz & $257.14 \pm 20.54$ & $250.36 \pm 18.26$ & 0.54 \\
N2 FCz & $255.05 \pm 20.06$ & $245.41 \pm 13.42$ & 0.28 \\
N2 Cz & $253.27 \pm 16.12$ & $248.86 \pm 13.09$ & 0.75 \\
N2 Pz & $253.14 \pm 23.90$ & $246.55 \pm 20.24$ & 0.38 \\
P3 Fz & $371.27 \pm 31.24$ & $366.36 \pm 28.54$ & 0.74 \\
P3 FCz & $366.55 \pm 29.86$ & $365.23 \pm 28.85$ & 0.85 \\
P3 Cz & $368.59 \pm 31.25$ & $369.41 \pm 26.80$ & 0.71 \\
P3 Pz & $377.18 \pm 27.82$ & $372.23 \pm 33.70$ & 0.96 \\
\hline V 345 & & & \\
\hline
\end{tabular}

Values are presented as mean \pm standard deviation.

$\mathrm{CTQ}$, childhood trauma questionnaire; Fz, frontal; Cz, central; Pz, parietal; FCz, fronto-central.

B

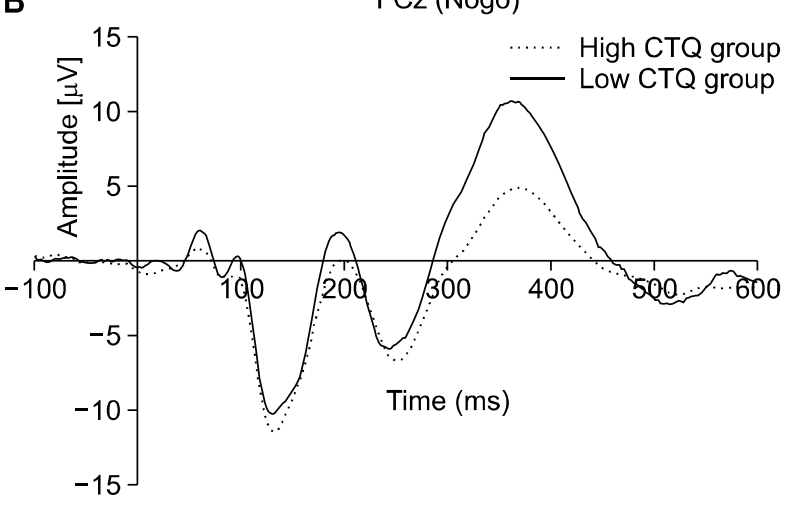

D

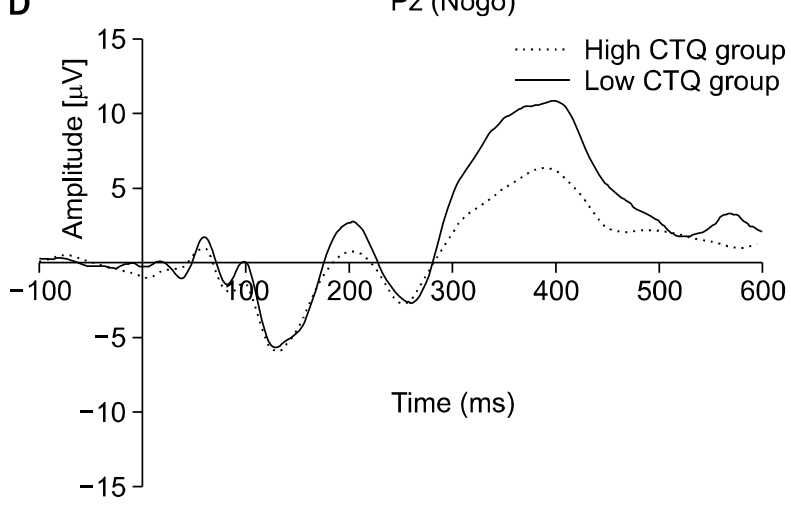

Fig. 1. Comparison of the amplitudes and latencies in Nogo condition. Grand average of P3 at the Fz (A), FCz (B), Cz (C), and Pz (D) electrodes for the low and high CTQ groups.

CTQ, childhood trauma questionnaire; Fz, frontal; Cz, central; Pz, parietal; FCz, fronto-central. 
outcomes. Go accuracy was significantly low in the high CTQ group. There were no significant differences in other behavioral outcomes between the two groups.

\section{Event-related Potentials}

\section{Amplitude and latency}

As there were no group differences in the latencies of the N2 and P3 components in the Nogo condition, the following analysis focused on the amplitude of each component. In the N2 amplitude, there was no significant difference between the two groups $(\mathrm{F}=0.016, \mathrm{df}=1, p=$ 0.901). In the $\mathrm{P} 3$ amplitude, there was a significant main effect of group ( $\mathrm{F}=10.967, \mathrm{df}=1, p=0.002)$. The main effects of the electrode site were significant $(\mathrm{F}=9.958, \mathrm{df}=$ $3, p<0.001)$. Table 3 presents the amplitude and latency data for Nogo N2 and P3. The high CTQ group showed significantly low amplitudes in Nogo P3 at all electrodes $(\mathrm{Fz}, p=0.003 ; \mathrm{FCz}, p=0.002 ; \mathrm{Cz}, p=0.003 ; \mathrm{Pz}, p=$ 0.002) (Table 3, Fig. 1).

\section{Correlations}

In the correlation analysis between the clinical measurements and ERP data for all participants, Nogo P3 amplitudes at the $\mathrm{FCz}$ and $\mathrm{Pz}$ were negatively correlated with the total CTQ score $(r=-0.321, p=0.034 ; r=-0.349$, $p=0.020$, respectively). There was also a negative tendency between other Nogo P3 amplitudes and the total CTQ score $(\mathrm{Fz}, \mathrm{r}=-0.296, p=0.051 ; \mathrm{Cz}, \mathrm{r}=-0.287, p=$

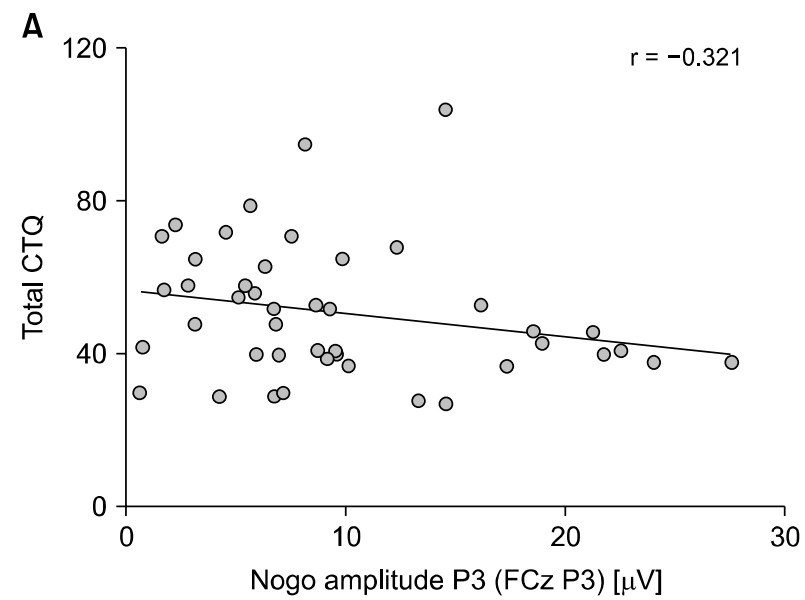

0.059) (Fig. 2).

\section{Source P300 of Nogo condition}

Source analysis of the Nogo P3 revealed decreased source densities of the cuneus (BA 18), posterior cingulate (BA 31), precuneus (BA 31), supramarginal gyrus (BA 40), and lingual gyrus (BA 18) in the high CTQ group ( $p<$ 0.01 ; Fig. 3) compared to the low CTQ group. Detailed information on the statistical values and voxel coordinates is provided in Table 4.

\section{DISCUSSION}

This study investigated Nogo ERP amplitudes and latencies during tasks in patients with MDD with or without a history of severe trauma. As hypothesized, the high CTQ group showed significantly attenuated Nogo ERP amplitudes in the present study. First, the high CTQ groups showed significantly decreased Nogo P3 amplitudes at all electrodes. Second, Nogo P3 amplitudes in the frontocentral and parietal electrodes were negatively correlated with the severity of childhood trauma. Third, the source activity of the significantly different Nogo P3 amplitudes was shown to be reduced in the region associated with these electrodes.

As expected, depressed patients with higher childhood trauma had decreased Nogo P3 amplitudes in all electrodes. Additionally, the higher the severity of childhood trauma, the lower the Nogo P3 amplitudes at the

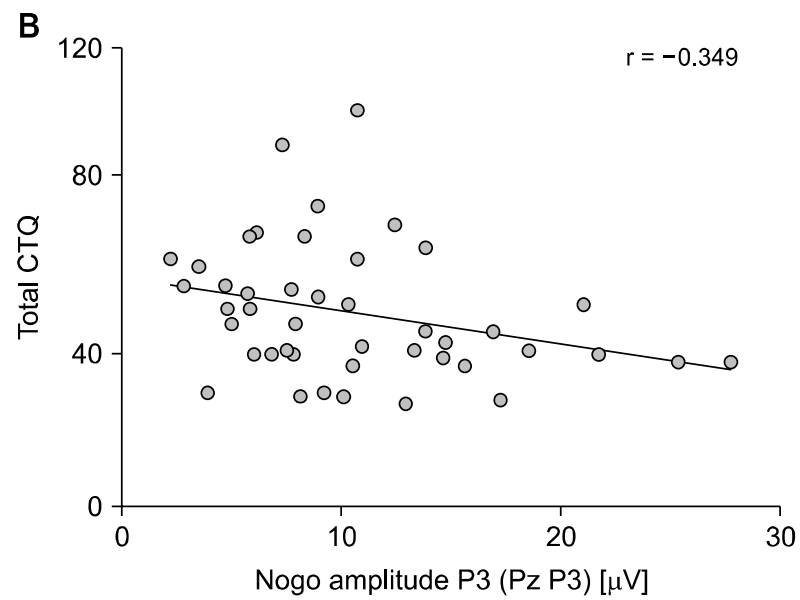

Fig. 2. The correlation between electrodes with total CTQ scores in all paticipants. Nogo P3 amplitudes at the FCz (A) and Pz (B) electrodes were negatively correlated with the total CTQ score.

CTQ, childhood trauma questionnaire; Pz, parietal; FCz, fronto-central. 
A Precuneus
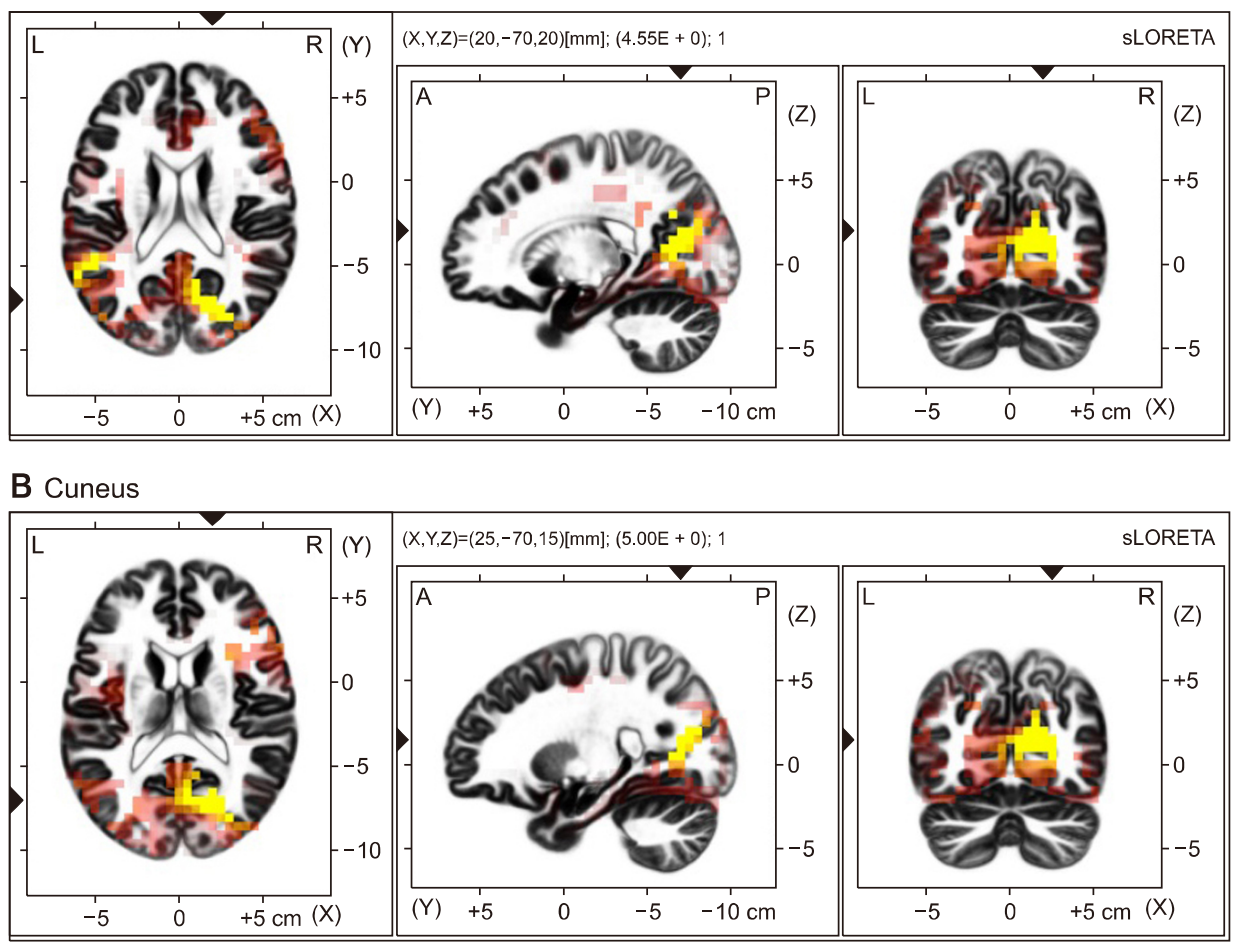

C Lingual gyrus

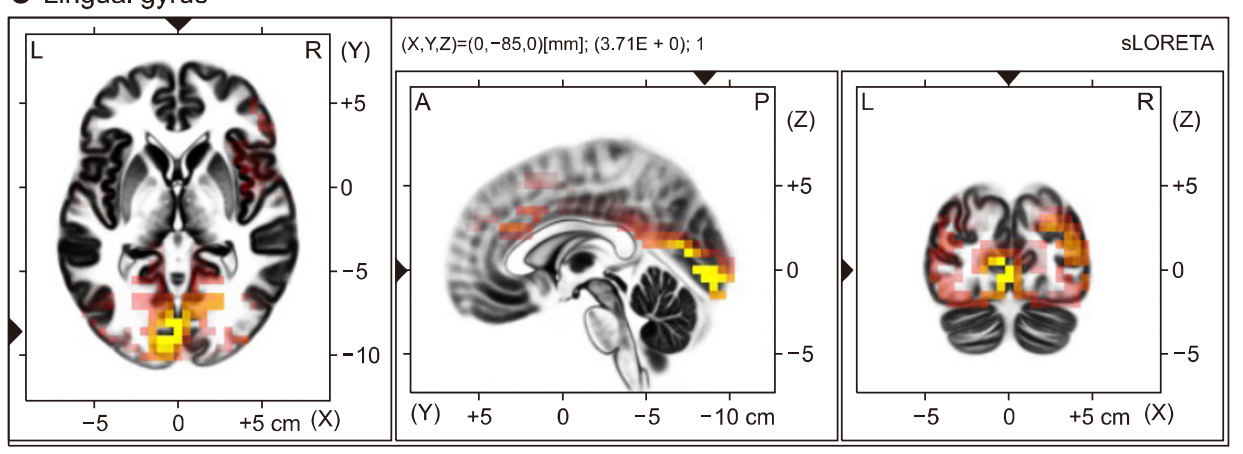

D Posterior cingulate

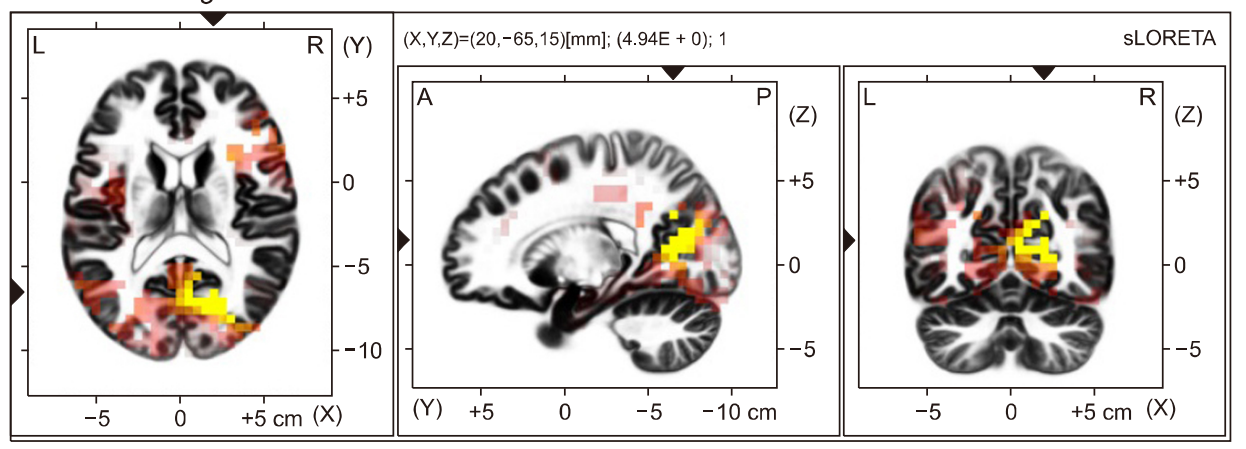

Fig. 3. Differences in the source activity of the Nogo P3 activity between high and low CTQ group in the precuneus $(A)$, cuneus $(B)$, lingual gyrus $(C)$, posterior cingulate (D) and supramarginal gyrus (E). The yellow color highlights the significant difference of the source activity of the Nogo P3 in the high CTQ group.

$\mathrm{CTQ}$, childhood trauma questionnaire.

frontocentral and parietal electrodes in the present study. The attenuation of Nogo P3 amplitudes is known to be related to behavioral disinhibition or impulsivity in many psychiatric diseases $[34,37,54,55]$. Our results are con- sistent with those of previous studies that included various populations of depression patients with a reduced Nogo P3 amplitude, which impairs inhibitory control $[54,56]$. Considering that the participants with childhood trauma 
E Supramarginal gyrus

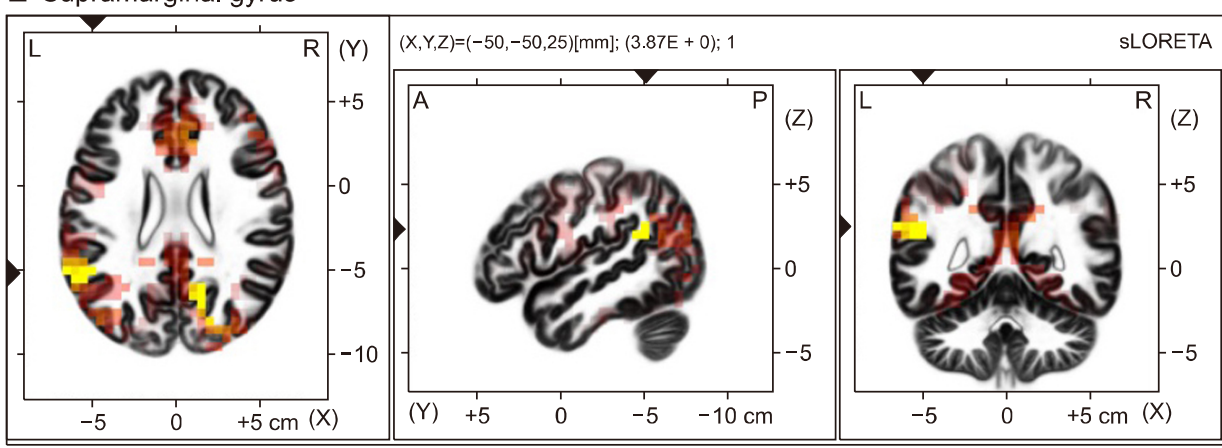

Fig. 3. Continued.

Table 4. Brain regions showing significant differences of Nogo P3 source activity between low and high CTQ groups

\begin{tabular}{|c|c|c|c|c|c|c|c|c|}
\hline \multirow{2}{*}{ ROI (structure) } & \multirow{2}{*}{$\begin{array}{c}\text { Brodmann } \\
\text { area }\end{array}$} & \multicolumn{3}{|c|}{ MNI coordinates } & \multicolumn{3}{|c|}{ Talairach coordinates } & \multirow{2}{*}{$\mathrm{t}$} \\
\hline & & $x$ & Y & Z & $x$ & Y & Z & \\
\hline Cuneus & 18 & 25 & -70 & 15 & 25 & -67 & 17 & $-5.05^{\mathrm{a}}$ \\
\hline Posterior cingulate & 31 & 20 & -65 & 15 & 20 & -62 & 17 & $-4.88^{\mathrm{a}}$ \\
\hline Precuneus & 31 & 20 & -70 & 20 & 20 & -67 & 22 & $-4.62^{\mathrm{a}}$ \\
\hline Supramarginal gyrus & 40 & -50 & -50 & 25 & -50 & -47 & 25 & $-4.11^{\mathrm{a}}$ \\
\hline Lingual gyrus & 18 & 0 & -85 & 0 & 0 & -82 & 4 & $-3.92^{\mathrm{a}}$ \\
\hline
\end{tabular}

CTQ, childhood trauma questionnaire; ROI, region of interest; $\mathrm{MNI}$, montreal neurological institute.

${ }^{\mathrm{a}} \mathrm{p}<0.01$.

seem to have difficulties in impulse control and behavioral inhibition compared to those without trauma [11], our results that the high CTQ group had attenuated Nogo P3 amplitudes might be plausible.

Surprisingly, there was no significant difference in BIS between the high and low CTQ groups. This might be due to the bias of self-report scales, or it might not have fully reflected our patients' impulsivity. Unexpectedly, there was no difference in the performances of Go/Nogo tasks between the two groups, excluding Go accuracy. No difference in the performances of Go/Nogo tasks might be caused by task difficulties [57]. Our Nogo tasks were too easy to differentiate performance, reflecting behavioral disinhibition between the high and low CTQ groups. ERP also reflects the high-order cognitive function of the behavioral control such as neural representation or task demands [58], so it may reflect more fundamental deficit of the behavioral control than the behavioral data itself. Although the difference was not statistically significant, the false alarm rate of the high CTQ group was higher than that of the low CTQ group.

Interestingly, the high CTQ group had significantly higher ALS scores in this study. These results imply that depressed patients with high CTQ experience more affec- tive dysregulation. The results were consistent with previous studies showing that higher childhood trauma can contribute to the development of emotional dysregulation [59-61]. It can be inferred that such affective dysregulation is associated with interpersonal trauma and post-traumatic stress [59]. Brain systems related to emotional regulation are shaped by early experience and reflect developmental history. Therefore, it is possible that early life adversity changes perceptual and cognitive appraisals related to threat [62]. As behavioral inhibition could be one of the phenotypes of emotional dysregulation, Nogo P3 might also reflect the affective lability or emotional regulation related to poor impulse control, although the ALS score was not correlated with Nogo P3 ERP in the present study. In addition, when children with ADHD are exposed to negative emotional situations, there is an increased need for top-down inhibitory control, which is reflected by the change in Nogo P3 amplitude [63]. Patients with affective lability similarly showed attenuation of the Nogo P3 amplitude [34,55]. In this regard, the reduction in the Nogo P3 amplitudes in the present study might reflect the inhibitory process of emotions in patients with depression who had suffered childhood trauma. Moreover, patients with affective lability similarly showed attenu- 
ation of the Nogo P3 amplitude [34,55]. It may be inferred that the high CTQ groups had more affective lability due to impairment of this process. Because there was no significant correlation between ALS and Nogo ERP in the study, the above speculation should be supported by further studies.

In this study, depressed patients with high CTQ showed significantly decreased Nogo P3 source activities compared to those with low CTQ in the cuneus, posterior cingulate, precuneus, supramarginal gyrus, and lingual gyrus. The results also support our suggestion that depressed patients with severe trauma might have difficulty in inhibitory deficits. The lingual gyrus is one of the activated regions in error processing, inhibition function, and divergent thinking in healthy control studies $[64,65]$. The gray matter volume of the cuneus is positively correlated with the inhibitory control [66] and the reduced volume of the precuneus is associated with higher impulsive sensitivity [67]. The posterior cingulate is also associated with response inhibition $[65,68]$, and the decreased volume or functional connectivity of this region is related to higher impulsivity $[69,70]$. It is noteworthy that the posterior cingulate and precuneus are part of the hub region of the default mode network (DMN) [71]. Many previous studies have pointed out that childhood trauma history might be linked to altered network connectivity, including the DMN $[39,72,73]$. Although our study has not been conducted in the resting state, some studies conducted with tasks associated with executive function and working memory also found altered DMN activation in groups with higher early life stress [73]. Decreased activity in these regions is associated with inferior performance during cognitive tasks $[74,75]$. This suggests that the severity of childhood trauma might affect the activation of default mode networks such as the posterior cingulate and precuneus in the present study. Moreover, considering that the posterior cingulate is engaged in various cognitive functions such as learning, memory, and reward [76], childhood trauma might affect efficient network connectivity, leading to impaired cognitive functions. The supramarginal gyrus is widely known to contribute to phonological word processing and auditory working memory [77-81]. Considering that our Go/Nogo paradigm has a task with auditory stimuli, deactivation of the supramarginal gyrus might affect impaired response inhibition by the dysfunctional auditory working memory process.
This suggests that the attenuated Nogo P3 amplitude and the neural activity of the relevant region might reflect a reduced cognitive efficiency for impulse control in depression with childhood trauma. That is, early childhood trauma leads to chronic stress, which might affect brain function and efficiency to regulate emotional response [82-84]. Considering the functions of the supramarginal gyrus and the precuneus, our study noted the role of parietal lobe related to the difficulty in behavioral inhibition shown frequently in patients with childhood trauma. The finding in present study that there was significantly negative correlation between the total CTQ and Nogo P3 amplitude at $\mathrm{Pz}$ also supports our point. In previous studies, childhood trauma was highly associated with decreased frontal lobe activity measured by Nogo P3, which might reflect poor cognitive control in the group with severe trauma $[36,37]$. Unexpectedly, there was no difference in frontal lobe activity between MDD patients with high and low CTQ in the present study. This might be due to the fact that both the groups were suffering from depression at the time of the study. Many studies have reported that patients with depression show frontal lobe dysfunction and alterations in frontal lobe activity [85-88]. Therefore, it could be assumed that the difference in frontal lobe activity affected by childhood trauma might not be very statistically significant in this study.

This study had several limitations. First, the results were obtained with relatively few participants compared to other studies. Future studies should include more participants to verify the present results. Second, both groups were not matched for age, although we controlled this mismatch by the variable as a covariate in MANOVA. Third, comorbidities such as anxiety disorder and ADHD in each patient were not sufficiently considered. These diseases have a high coexistence rate with MDD in clinical practice, and therefore, it is difficult to completely exclude them. However, other major psychiatric disorders were part of the exclusion criteria. Further studies to consider comorbidities are necessary. Finally, since our study mainly used self-reporting scales in psychological assessment, it is possible that the measurements of the present study did not fully reflect the objective clinical data of the participants.

Despite these limitations, this study might be worthwhile, as this is the first attempt, to the best of our knowledge, to explore whether Nogo ERPs differ between pa- 
tients with MDD who experience very severe trauma and those who experience less severe trauma. Furthermore, the attenuated Nogo P3 amplitudes in depressed patients with high childhood trauma might reflect inhibitory dysfunction and emotional dysregulation in patients with higher early life stress. In particular, our source activity analysis also showed deactivated regions related to childhood trauma and poor inhibitory function. This suggests the possibility of using Nogo ERP as a biomarker to determine whether a patient with depression has suffered severe trauma. It is necessary to examine whether our findings will be applicable to a large sample size in future studies.

\section{- Funding}

This work has supported by a grant (No. 2018R1C1B50 44454, 2020R111A3068017, 2020R111A3A04036435) awarded by the Basic Science Research Program through the National Research Foundation of Korea (NRF) and funded by the Ministry of Education. This study was also supported by Soonchunhyang University.

\section{- Conflicts of Interest}

No potential conflict of interest relevant to this article was reported.

\section{Author Contributions}

Conceptualization: In Soo Heo, Se-Hoon Shim, Ji Sun Kim. Data acquisition: In Soo Heo. Formal analysis: In Soo Heo, Hee-Jung Yoon. Funding: Young Joon Kwon, Hwa-Young Lee, Se-Hoon Shim, Ji Sun Kim. Supervision: Young Joon Kwon, Hwa-Young Lee, Ho Sung Lee, Se-Hoon Shim, Ji Sun Kim. Writing-original draft: In Soo Heo. Writing - review \& editing: In Soo Heo, Se-Hoon Shim, Ji Sun Kim.

\section{ORCID}

In $\mathrm{Soo} \mathrm{HeO}$

Young Joon Kwon https://orcid.org/0000-0003-3236-5744 Hwa-Young Lee Ho Sung Lee Hee-Jung Yoon Se-Hoon Shim Ji Sun Kim

\section{REFERENCES}

1. American Psychiatric Association. Diagnostic and statistical manual of mental disorders: DSM-5. Arlington:American PSychiatric Association;2013.

2. World Health Organization. Preventing child maltreatment: a guide to taking action and generating evidence. Geneva:World Health Organization;2006.

3. Terr LC. Childhood traumas: an outline and overview. Am J Psychiatry 1991;148:10-20.

4. Heim C, Nemeroff CB. The role of childhood trauma in the neurobiology of mood and anxiety disorders: preclinical and clinical studies. Biol Psychiatry 2001;49:1023-1039.

5. Ekinci S, Kandemir H. Childhood trauma in the lives of substance-dependent patients: the relationship between depression, anxiety and self-esteem. Nord J Psychiatry 2015;69:249253.

6. Brodsky BS, Oquendo M, Ellis SP, Haas GL, Malone KM, Mann JJ. The relationship of childhood abuse to impulsivity and suicidal behavior in adults with major depression. Am J Psychiatry 2001;158:1871-1877.

7. Zatti C, Rosa V, Barros A, Valdivia L, Calegaro VC, et al. Childhood trauma and suicide attempt: a meta-analysis of longitudinal studies from the last decade. Psychiatry Res 2017;256. 353-358.

8. Perez CM, Widom CS. Childhood victimization and long-term intellectual and academic outcomes. Child Abuse Negl 1994; 18:617-633.

9. Bücker J, Kapczinski F, Post R, Ceresér KM, Szobot C, Yatham $\mathrm{LN}$, et al. Cognitive impairment in school-aged children with early trauma. Compr Psychiatry 2012;53:758-764.

10. Dunn EC, Busso DS, Raffeld MR, Smoller JW, Nelson CA, Doyle $\mathrm{AE}$, et al. Does developmental timing of exposure to child maltreatment predict memory performance in adulthood? Results from a large, population-based sample. Child Abuse Neg/ 2016;51:181-191.

11. Marshall DF, Passarotti AM, Ryan KA, Kamali M, Saunders EF, Pester B, et al. Deficient inhibitory control as an outcome of childhood trauma. Psychiatry Res 2016;235:7-12.

12. Roy A. Childhood trauma and impulsivity. Possible relevance to suicidal behavior. Arch Suicide Res 2005:9:147-151.

13. Richard-Lepouriel H, Kung AL, Hasler R, Bellivier F, Prada P, Gard S, et al. Impulsivity and its association with childhood trauma experiences across bipolar disorder, attention deficit hyperactivity disorder and borderline personality disorder. J Affect Disord 2019;244:33-41.

14. Narvaez JC, Magalhães PV, Trindade EK, Vieira DC, KauerSant'anna M, Gama CS, et al. Childhood trauma, impulsivity, and executive functioning in crack cocaine users. Compr Psychiatry 2012,53:238-244

15. Aas M, Aminoff SR, Vik Lagerberg T, Etain B, Agartz I, Andreassen OA, et al. Affective lability in patients with bipolar disorders is associated with high levels of childhood trauma. Psychiatry Res 2014;218:252-255. 
16. Marwaha S, Gordon-Smith K, Broome M, Briley PM, Perry A, Forty $\mathrm{L}$, et al. Affective instability, childhood trauma and major affective disorders. J Affect Disord 2016;190:764-771.

17. Crowell SE, Beauchaine TP, Linehan MM. A biosocial developmental model of borderline personality: elaborating and extending Linehan's theory. Psychol Bull 2009;135:495-510.

18. Wonderlich SA, Rosenfeldt S, Crosby RD, Mitchell JE, Engel SG, Smyth J, et al. The effects of childhood trauma on daily mood lability and comorbid psychopathology in bulimia nervosa. J Trauma Stress 2007;20:77-87.

19. Nanni V, Uher R, Danese A. Childhood maltreatment predicts unfavorable course of illness and treatment outcome in depression: a meta-analysis. Am J Psychiatry 2012;169:141-151.

20. Kaczmarczyk M, Wingenfeld K, Kuehl LK, Otte C, Hinkelmann K. Childhood trauma and diagnosis of major depression: association with memory and executive function. Psychiatry Res 2018;270:880-886.

21. Kaufman J, Plotsky PM, Nemeroff CB, Charney DS. Effects of early adverse experiences on brain structure and function: clinical implications. Biol Psychiatry 2000;48:778-790.

22. Tomoda A, Suzuki H, Rabi K, Sheu YS, Polcari A, Teicher MH. Reduced prefrontal cortical gray matter volume in young adults exposed to harsh corporal punishment. Neuroimage 2009; 47(Supp/ 2):T66-T71.

23. Cohen RA, Grieve S, Hoth KF, Paul RH, Sweet L, Tate D, et al. Early life stress and morphometry of the adult anterior cingulate cortex and caudate nuclei. Biol Psychiatry 2006;59:975982.

24. Hart H, Rubia K. Neuroimaging of child abuse: a critical review. Front Hum Neurosci 2012;6:52.

25. Hanson JL, Chung MK, Avants BB, Shirtcliff EA, Gee JC, Davidson RJ, et al. Early stress is associated with alterations in the orbitofrontal cortex: a tensor-based morphometry investigation of brain structure and behavioral risk. I Neurosci 2010;30:7466-7472.

26. Everaerd D, Klumpers F, Zwiers M, Guadalupe T, Franke B, van Oostrom I, et al. Childhood abuse and deprivation are associated with distinct sex-dependent differences in brain morphology. Neuropsychopharmacology 2016;41:1716-1723.

27. Teicher MH, Andersen SL, Polcari A, Anderson CM, Navalta $\mathrm{CP}$, Kim DM. The neurobiological consequences of early stress and childhood maltreatment. Neurosci Biobehav Rev 2003;27:33-44.

28. Teicher MH, Tomoda A, Andersen SL. Neurobiological consequences of early stress and childhood maltreatment: are results from human and animal studies comparable? Ann N $Y$ Acad Sci 2006; 1071:313-323.

29. Lee YJ, Jeong MY, Kim JH, Kim JS. Associations between the mismatch-negativity potential and symptom severity in medication-naive children and adolescents with symptoms of attention deficit/hyperactivity disorder. Clin Psychopharmacol Neurosci 2020;18:249-260.

30. Kim JS, Kwon YJ, Lee HY, Lee HS, Kim S, Shim SH. Mismatch negativity indices as a prognostic factor for remission in schizophrenia. Clin Psychopharmacol Neurosci 2020;18: 127-135.

31. Sur S, Sinha VK. Event-related potential: an overview. Ind Psychiatry J 2009;18:70-73.

32. Bokura H, Yamaguchi S, Kobayashi S. Electrophysiological correlates for response inhibition in a Go/NoGo task. Clin Neurophysiol 2001;112:2224-2232.

33. Munro GE, Dywan J, Harris GT, McKee S, Unsal A, Segalowitz S). Response inhibition in psychopathy: the frontal N2 and P3. Neurosci Lett 2007;418:149-153.

34. Guan M, Liao Y, Ren H, Wang X, Yang Q, Liu X, et al. Impaired response inhibition in juvenile delinquents with antisocial personality characteristics: a preliminary ERP study in a Go/Nogo task. Neurosci Lett 2015;603:1-5.

35. Kiehl KA, Smith AM, Hare RD, Liddle PF. An event-related potential investigation of response inhibition in schizophrenia and psychopathy. Biol Psychiatry 2000;48:210-221.

36. Wu J, Ge Y, Shi Z, Duan X, Wang L, Sun X, et al. Response inhibition in adolescent earthquake survivors with and without posttraumatic stress disorder: a combined behavioral and ERP study. Neurosci Lett 2010;486:117-121.

37. Kim S, Kim JS, Jin MJ, Im CH, Lee SH. Dysfunctional frontal lobe activity during inhibitory tasks in individuals with childhood trauma: an event-related potential study. Neuroimage Clin 2017; 17:935-942.

38. Wu H, Wu C, Wu F, Zhan Q, Peng H, Wang J, et al. Covariation between childhood-trauma related resting-state functional connectivity and affective temperaments is impaired in individuals with major depressive disorder. Neuroscience 2021;453:102-112.

39. Yu M, Linn KA, Shinohara RT, Oathes DJ, Cook PA, Duprat R, et al. Childhood trauma history is linked to abnormal brain connectivity in major depression. Proc Natl Acad Sci U S A 2019;116:8582-8590.

40. Kim JS, Kim S, Jung W, Im CH, Lee SH. Auditory evoked potential could reflect emotional sensitivity and impulsivity. Sci Rep 2016;6:37683.

41. Bernstein DP, Stein JA, Newcomb MD, Walker E, Pogge D, Ahluvalia T, et al. Development and validation of a brief screening version of the Childhood Trauma Questionnaire. Child Abuse Neg/ 2003;27:169-190.

42. Kim D, Park SC, Yang H, Oh DH. Reliability and validity of the Korean version of the childhood trauma questionnaire-short form for psychiatric outpatients. Psychiatry Investig 2011;8: 305-311.

43. Beck AT, Steer RA, Brown G. BDI-II, Beck depression inventory: manual. San Antonio:Psychological Corp.;1996.

44. Whisman MA, Perez JE, Ramel W. Factor structure of the Beck Depression Inventory-Second Edition (BDI-II) in a student sample. J Clin Psychol 2000;56:545-551.

45. Spielberger C, Gorsuch R, Lushene R, Vagg P, Jacobs G. Manual for the state-trait anxiety inventory. Palo Alto:Consulting 
Psychologists Press; 1983.

46. Kim J, Shin D. A study based on the standardization of the STA/ for Korea. New Med) 1978;21:69-75.

47. Patton JH, Stanford MS, Barratt ES. Factor structure of the Barratt impulsiveness scale. JClin Psychol 1995;51:768-774.

48. Lee SR, Lee WH, Park JS, Kim SM, Kim JW, Shim JH. The study on reliability and validity of Korean version of the Barratt impulsiveness scale-11-revised in nonclinical adult subjects. J Korean Neuropsychiatr Assoc 2012;51:378-386.

49. Aas M, Henry C, Bellivier F, Lajnef M, Gard S, Kahn JP, et al. Affective lability mediates the association between childhood trauma and suicide attempts, mixed episodes and co-morbid anxiety disorders in bipolar disorders. Psychol Med 2017;47: 902-912.

50. Oliver MN, Simons JS. The affective lability scales: development of a short-form measure. Pers Individ Dif 2004;37:1279. 1288.

51. Pascual-Marqui RD. Standardized low-resolution brain electromagnetic tomography (sLORETA): technical details. Methods Find Exp Clin Pharmacol 2002;24 Supp/ D:5-12.

52. Fuchs M, Kastner J, Wagner M, Hawes S, Ebersole JS. A standardized boundary element method volume conductor model. Clin Neurophysiol 2002;113:702-712.

53. Brett M. The MNI brain and the Talairach atlas [Internet]. Cambridge: MRC Cognition and Brain Sciences Unit; 2002 [cited at 2021 Apr 23]. Available from: https://imaging.mrccbu.cam.ac.uk/imaging/MniTalairach.

54. Ruchsow M, Groen G, Kiefer M, Beschoner P, Hermle L, Ebert $\mathrm{D}$, et al. Electrophysiological evidence for reduced inhibitory control in depressed patients in partial remission: a Go/Nogo study. Int J Psychophysiol 2008;68:209-218.

55. Ruchsow M, Groen G, Kiefer M, Buchheim A, Walter H, Martius $\mathrm{P}$, et al. Response inhibition in borderline personality disorder: event-related potentials in a Go/Nogo task. J Neural Transm (Vienna) 2008;115:127-133.

56. Zhang BW, Zhao L, Xu J. Electrophysiological activity underlying inhibitory control processes in late-life depression: a Go/Nogo study. Neurosci Lett 2007;419:225-230.

57. Benikos N, Johnstone SJ, Roodenrys SJ. Varying task difficulty in the Go/Nogo task: the effects of inhibitory control, arousal, and perceived effort on ERP components. Int I Psychophysiol 2013;87:262-272.

58. Polich J. Updating P300: an integrative theory of P3a and P3b. Clin Neurophysiol 2007; 118:2128-2148.

59. Dvir Y, Ford JD, Hill M, Frazier JA. Childhood maltreatment, emotional dysregulation, and psychiatric comorbidities. Harv Rev Psychiatry 2014;22:149-161.

60. Shipman K, Zeman J, Penza S, Champion K. Emotion management skills in sexually maltreated and nonmaltreated girls: a developmental psychopathology perspective. Dev Psychopathol 2000; 12:47-62.

61. Shipman K, Edwards A, Brown A, Swisher L, Jennings E. Managing emotion in a maltreating context: a pilot study ex- amining child neglect. Child Abuse Negl 2005;29:10151029.

62. Andersen SL, Lyss PJ, Dumont NL, Teicher MH. Enduring neurochemical effects of early maternal separation on limbic structures. Ann N Y Acad Sci 1999;877:756-759.

63. López-Martín S, Albert J, Fernández-Jaén A, Carretié L. Response inhibition during emotional contexts in children with ADHD: neural and behavioral data. In: XII International Conference on Cognitive Neuroscience (ICON-XII); 27 Jul-31 Jul, 2014; Brisbane, Australia.

64. Zhang L, Qiao L, Chen Q, Yang W, Xu M, Yao X, et al. Gray matter volume of the lingual gyrus mediates the relationship between inhibition function and divergent thinking. Front Psychol 2016;7:1532.

65. Menon V, Adleman NE, White CD, Glover GH, Reiss AL. Error-related brain activation during a Go/NoGo response inhibition task. Hum Brain Mapp 2001;12:131-143.

66. Haldane M, Cunningham G, Androutsos C, Frangou S. Structural brain correlates of response inhibition in Bipolar Disorder I. J Psychopharmacol 2008;22:138-143.

67. Fuentes $P$, Barrós-Loscertales A, Bustamante JC, Rosell P, Costumero V, Ávila C. Individual differences in the Behavioral Inhibition System are associated with orbitofrontal cortex and precuneus gray matter volume. Cogn Affect Behav Neurosci 2012;12:491-498.

68. Horn NR, Dolan M, Elliott R, Deakin JF, Woodruff PW. Response inhibition and impulsivity: an fMRI study. Neuropsychologia 2003;41:1959-1966.

69. Wang J, Fan Y, Dong Y, Ma M, Ma Y, Dong Y, et al. Alterations in brain structure and functional connectivity in alcohol dependent patients and possible association with impulsivity. PLoS One 2016;11:e0161956.

70. Yang R, Gao C, Wu X, Yang J, Li S, Cheng H. Decreased functional connectivity to posterior cingulate cortex in major depressive disorder. Psychiatry Res Neuroimaging 2016;255: 15-23.

71. Tomasi D, Volkow ND. Association between functional connectivity hubs and brain networks. Cereb Cortex 2011;21: 2003-2013.

72. Daniels JK, Frewen P, McKinnon MC, Lanius RA. Default mode alterations in posttraumatic stress disorder related to early-life trauma: a developmental perspective. J Psychiatry Neurosci 2011;36:56-59.

73. Philip NS, Sweet LH, Tyrka AR, Carpenter SL, Albright SE, Price $\mathrm{LH}$, et al. Exposure to childhood trauma is associated with altered n-back activation and performance in healthy adults: implications for a commonly used working memory task. Brain Imaging Behav 2016;10:124-135.

74. Sonuga-Barke EJ, Castellanos FX. Spontaneous attentional fluctuations in impaired states and pathological conditions: a neurobiological hypothesis. Neurosci Biobehav Rev 2007;31: 977-986.

75. Weissman DH, Roberts KC, Visscher KM, Woldorff MG. The 
neural bases of momentary lapses in attention. Nat Neurosci 2006;9:971-978.

76. Pearson JM, Heilbronner SR, Barack DL, Hayden BY, Platt ML. Posterior cingulate cortex: adapting behavior to a changing world. Trends Cogn Sci 2011;15:143-151.

77. Newman RL, Joanisse MF. Modulation of brain regions involved in word recognition by homophonous stimuli: an $\mathrm{fMRI}$ study. Brain Res 2011;1367:250-264.

78. Sliwinska MW, Khadilkar M, Campbell-Ratcliffe J, Quevenco F, Devlin JT. Early and sustained supramarginal gyrus contributions to phonological processing. Front Psychol 2012;3: 161.

79. Howard D. Language in the human brain. In: Rugg MD, editor. Cognitive neuroscience. Cambridge:The MIT Press;1997. p.277-304.

80. Vines BW, Schnider NM, Schlaug G. Testing for causality with transcranial direct current stimulation: pitch memory and the left supramarginal gyrus. Neuroreport 2006; 17:1047-1050.

81. Awh E, Jonides J, Smith EE, Schumacher EH, Koeppe RA, Katz S. Dissociation of storage and rehearsal in verbal working memory: evidence from positron emission tomography. Psychol Sci 1996; 7:25-31.
82. McEwen BS, Gianaros PJ. Central role of the brain in stress and adaptation: links to socioeconomic status, health, and disease. Ann N Y Acad Sci 2010;1186:190-222.

83. Mariotti A. The effects of chronic stress on health: new insights into the molecular mechanisms of brain-body communication. Future SCi OA 2015;1:FSO23.

84. Kim P, Evans GW, Angstadt M, Ho SS, Sripada CS, Swain JE, et al. Effects of childhood poverty and chronic stress on emotion regulatory brain function in adulthood. Proc Natl Acad Sci U S A 2013;110:18442-18447.

85. Rigucci S, Serafini G, Pompili M, Kotzalidis GD, Tatarelli R. Anatomical and functional correlates in major depressive disorder: the contribution of neuroimaging studies. World I Biol Psychiatry 2010;11(2 Pt 2):165-180.

86. George MS. Transcranial magnetic stimulation for the treatment of depression. Expert Rev Neurother 2010;10:1761-1772.

87. Kumar A, Bilker W, Jin Z, Udupa J. Atrophy and high intensity lesions: complementary neurobiological mechanisms in late-life major depression. Neuropsychopharmacology 2000;22:264-274.

88. Pandya M, Altinay M, Malone DA Jr, Anand A. Where in the brain is depression? Curr Psychiatry Rep 2012;14:634-642. 